\title{
Study of MG49-PMMA Based Solid Polymer Electrolyte
}

\author{
A. Ahmad ${ }^{*}, 1,2$, M.Y.A. Rahman ${ }^{* 3}$, M.S. Su'ait ${ }^{1,2}$ and H. Hamzah ${ }^{1,2}$ \\ ${ }^{I}$ Polymer Research Center, Faculty of Sciences and Technology, Universiti Kebangsaan Malaysia, 43600, Bangi, \\ Selangor, Malaysia \\ ${ }^{2}$ School of Chemical Sciences and Food Technology, Faculty of Sciences and Technology, Universiti Kebangsaan \\ Malaysia, 43600, Bangi, Selangor, Malaysia \\ ${ }^{3}$ College of Engineering, Universiti Tenaga Nasional, 43009, Kajang, Selangor, Malaysia
}

\begin{abstract}
The studies of rubber-polymer blends as solid polymer electrolyte for electrochemical devices application have been investigated. The electrolyte films were prepared by solution casting technique. The effect of poly(methyl methacrylate) (PMMA) and lithium tetrafluoroborate $\left(\mathrm{LiBF}_{4}\right)$, salt concentration on chemical interaction, ionic conductivity, structure and morphology of $49 \%$ poly(methyl methacrylate)-grafted natural rubber (MG49) have been analyzed by using fourier transform infrared spectroscopy (FT-IR), electrochemical impedance spectroscopy (EIS), x-ray diffraction (XRD) and scanning electron microscopy (SEM). Infrared analysis showed that the interaction between oxygen atoms and lithium ion occurred at ether $(\mathrm{C}-\mathrm{O}-\mathrm{C})$ and carbonyl $(\mathrm{C}=\mathrm{O})$ group in the MMA host. The highest ionic conductivity for blended MG49-PMMA films is $8.3 \times 10^{-6} \mathrm{~S} \mathrm{~cm}^{-1}$ as compared to MG49 electrolyte with $9.6 \times 10^{-10} \mathrm{~S} \mathrm{~cm}^{-1}$ at $25 \mathrm{wt} . \% \mathrm{LiBF}_{4}$. The structural analysis showed the reduction of MMA crystallinity phase at the highest conductivity for both systems. Meanwhile, morphological analysis shows that recrystallization of $\mathrm{LiBF}_{4}$ salts have occurred in the electrolyte system after the optimum conductivity.
\end{abstract}

Keywords: $49 \%$ poly(methyl methacrylate)-grafted natural rubber (MG49), ionic conductivity, lithium tetrafluoroborate $\left(\mathrm{LiBF}_{4}\right)$, poly(methyl methacrylate) (PMMA), solid polymer electrolyte.

\section{INTRODUCTION}

The discovery of ionic conductivity in polymeric material doped with salt by Fenton et al. [1] in 1973 has led to the current rapid development of electrochemical devices application [2]. Recently, rubber polymer electrolytes had drawn the attention of many researchers [3-9]. Modified natural rubber has attractive attributes; it is free standing, flexible and has good elasticity. A suitable elasticity can result in flat and flexible films. Therefore, an excellent contact is expected between an electrolytic layer and an electrode in batteries system. Furthermore, modified natural rubber has low glass transition temperature $\left(T_{\mathrm{g}}\right)$ between $20^{\circ} \mathrm{C}$ to $-60^{\circ} \mathrm{C}$. Modified natural rubber shows soft elastomer characterization at room temperature, which contributes to the segmental motion of polymer host. Modified natural rubber with polar groups can also act as a polymeric solvent and the ionic conductivity value is expected to be higher as compared to glassy or crystalline state of polymer [2]. However, modified natural rubber such as epoxidized natural rubber (ENR) shows a drawback to its mechanical properties, such as slightly sticky and difficult to peel off from substrate $[3,4,10]$. On the other hand, MG49 is more free standing, flexible and has good elasticity. MG49 also has oxygen atom contributed by MMA monomer that has

*Address correspondence to these authors at the Polymer Research Center, Faculty of Sciences and Technology, Universiti Kebangsaan Malaysia, 43600, Bangi, Selangor, Malaysia; Tel: +60389215439;

E-mail: azizan@ukm.my or College of Engineering, Universiti Tenaga Nasional, 43009, Kajang, Selangor, Malaysia; Tel: +60389287262;

Fax:+60389212115; E-mail: Yusri@uniten.edu.my been grafted to polyisoprene chain. The oxygen atoms with a lone pair of electrons act as electron donor atoms in the structure of the polymer host. The interaction between the oxygen atoms and lithium ions of the metal salt forms a coordinate bond and generates polymer-salt complexes $[5,6]$. Previous studies on various MG were reported elsewhere $[5,7,8]$. However, MG based polymer electrolytes without plasticizers such as polypropylene carbonate (PC) and ethylene carbonate (EC) provide low ionic conductivity values. The presence of plasticizers has been proven to enhance the ionic conductivity value in polymer electrolyte. However, according to $\mathrm{Lu}$ et al. [10], the presence of plasticizers can easily corrode the lithium metal electrode in the electrochemical cell. In order to enhance conductivity value and electrochemical stability of the electrolyte, polymer blending between MG49-PMMA has been introduced. PMMA has been used as a polymer host since 1985 after being initiated by Iijima and co-workers [11] due to its high stability at lithium-electrolyte surface and its less reactivity towards the lithium electrode [12]. It induces a more favourable passivation film on the electrode surface. Therefore, a higher cycle ability of the lithium electrode in PMMA based electrolytes is expected. In addition, PMMA has a polar functional group in the side chains that shows high affinity for lithium ions. The oxygen atoms in the PMMA structure will provide a coordination site for lithium ion to transport $[8,12]$. This coordination site acts as a stiffener that fast ion transport, occurring through a continuous conduction path that does not affect the electrochemical stability of the electrolyte [13]. 
In this work, MG49 and polymer blends (50/50) with MG49-PMMA were doped with lithium tetrafluoroborate $\left(\mathrm{LiBF}_{4}\right)$ salt to prepare solid polymer electrolytes by solution blending via a casting technique. All samples were characterized by using Fourier transform spectroscopy (FTIR), AC electrochemical impedances spectroscopy (EIS), Xray diffraction (XRD) and scanning electron microscopy (SEM).

\section{EXPERIMENTAL}

\section{Materials}

MG49 was commercially obtained from Green HPSP (Malaysia) Sdn. Bhd. PMMA of low molecular weight ( $15,000 \mathrm{Mw}$ ) and $\mathrm{LiBF}_{4}$ was supplied by Fluka and Aldrich respectively. Organic solvents such as toluene and tetrahydrofuran (THF) were supplied by Systerm ChemAR. All the materials were used without further purification.

\section{Sample Preparation}

All the electrolyte samples were prepared by solution blending via a casting technique. A quantity of MG49 was dissolved in stoppered flasks containing toluene. After 24 hours, the solution was stirred using an efficient magnetic stirrer for the next 24 hours until the complete dissolution of MG49. PMMA solution was prepared in another stoppered flask containing toluene and stirred for 24 hours. These two solutions were then mixed together with continuous stirring for $24 \mathrm{~h}$ to obtain a homogeneous solution. $\mathrm{LiBF}_{4}$ salt was dissolved in THF for 12 hours in a separate flask by stirring. This solution was then mixed with MG49-PMMA solution for the next 24 hours with continuous stirring. The electrolyte solutions were casted onto a glass Petri dish and the solvent were allowed to slowly evaporate at room temperature. Residual solvents were then removed in vacuum oven for 48 hours at $50{ }^{\circ} \mathrm{C}$. The samples were then stored in a desiccator until further use. The same experimental procedure was repeated for different weight percentages of $\mathrm{LiBF}_{4}$. The same experimental procedure was also repeated for $\mathrm{MG} 49-\mathrm{LiBF}_{4}$ systems, except the addition of PMMA.

\section{Characterization}

FT-IR spectrum was recorded in a computer interfaced Perkin Elmer GX Spectrometer. The electrolyte was casted onto $\mathrm{NaCl}$ windows and analyzed in the frequency range of $4000 \mathrm{~cm}^{-1}$ to $400 \mathrm{~cm}^{-1}$ with the scanning resolution of $4 \mathrm{~cm}^{-1}$. The ionic conductivity measurements were carried out by EIS using High Frequency Resonance Analyzer (HFRA) model 1255 with applied frequency from $1 \mathrm{MHz}$ to $0.1 \mathrm{~Hz}$ at $1000 \mathrm{mV}$ amplitude. The disc shaped sample of $16 \mathrm{~mm}$ in diameter was sandwiched between two stainless steel block electrodes. The ionic conductivity $(\sigma)$ was calculated from the $R_{\mathrm{b}}$, the bulk resistance $\left(R_{\mathrm{b}}\right)$ was obtained from the intercept on real impedance axis ( $Z$ ' axis), the film thickness $(t)$ and contact area of the thin film $\left(A=\pi \mathrm{r}^{2}=\pi(1.60 \mathrm{~cm} / 2)^{2}=\right.$ $\left.2.01 \mathrm{~cm}^{2}\right)$, according to the equation $\sigma=\left[t /\left(A \cdot R_{\mathrm{b}}\right)\right]$. XRD model D-5000 Siemens was used to observe the appearance and disappearance of crystalline or amorphous phase as a function of salt content. The data were collected from the range of diffraction angle $2 \theta$ from $2^{\circ}$ to $80^{\circ}$ at scan rate $0.04^{\circ} \mathrm{s}^{-1}$. Surface morphology of sample was observed by using an SEM model Philips XL30 with 1000 magnification at $20 \mathrm{kV}$ electron beam. Sample was fractured in liquid nitrogen and coated with gold -coated in a gold-sputtering machine before the analysis. Analysis was performed at room temperature.

The $\left[\mathrm{O} / \mathrm{Li}^{+}\right]$ratio for a single polymer was calculated by equation:

$\left[\mathrm{O} / \mathrm{Li}^{+}\right]=$

$$
\frac{M_{\mathrm{p}} \times M_{W \mathrm{~s}} \times n_{\mathrm{p}}}{M_{\mathrm{s}} \times M_{W \mathrm{~m}}}
$$

where, $M_{\mathrm{p}}=$ Mass of polymer $(\mathrm{g}), M_{W \mathrm{~s}}=$ Molecular weight of salt $\left(\mathrm{g} \mathrm{mol}^{-1}\right), M_{\mathrm{s}}=$ Mass of salt $(\mathrm{g}), M_{W \mathrm{~m}}=$ Molecular weight of monomer $\left(\mathrm{g} \mathrm{mol}^{-1}\right), n_{\mathrm{p}}=$ number of oxygen atom per repeated unit monomer.

Whereas, the $\left[\mathrm{O} / \mathrm{Li}^{+}\right]$ratio for the polymer blend was calculated by equation [14]:

$$
\left[\mathrm{O} / \mathrm{Li}^{+}\right]=\frac{M_{\mathrm{T}} \times M_{W \mathrm{~s}}}{M_{\mathrm{s}} \times\left[\frac{M_{W m}}{n_{m}}+\frac{M_{W a}}{n_{\mathrm{a}}}+\frac{M_{W b}}{n_{\mathrm{b}}}\right]}
$$

where, $M_{\mathrm{T}}=$ Total Mass of polymer $(\mathrm{A}+\mathrm{B})(\mathrm{g}), M_{W \mathrm{~s}}=$ Molecular weight of salt $\left(\mathrm{g} \mathrm{mol}^{-1}\right), M_{\mathrm{s}}=$ Mass of salt $(\mathrm{g})$, $M_{W \mathrm{~m}}=$ Molecular weight of monomer $\left(\mathrm{g} \mathrm{mol}^{-1}\right), M_{W \mathrm{a}}=$ Molecular weight of monomer A $\left(\mathrm{g} \mathrm{mol}^{-1}\right), M_{W \mathrm{~b}}=$ Molecular weight of monomer $\mathrm{B}\left(\mathrm{g} \mathrm{mol}^{-1}\right), n_{\mathrm{m}}=$ Total number of oxygen atom per repeated unit monomer $(\mathrm{A}+\mathrm{B}), n_{\mathrm{a}}=$ number of oxygen atom per repeated unit monomer $\mathrm{A}, n_{\mathrm{b}}=$ number of oxygen atom per repeated unit monomer B.

\section{RESULTS AND DISCUSSION}

\section{FT-IR Analysis}

FT-IR spectroscopy technique is used to study the vibration energy of covalent bond and the interaction occurs in the polymer-salt complexes. The main focus on the oxygen atoms of the carbonyl $(\mathrm{C}=\mathrm{O})\left(1750 \mathrm{~cm}^{-1}-1730 \mathrm{~cm}^{-1}\right)$ and ether group (C-O-C) $\left(1300 \mathrm{~cm}^{-1}-1000 \mathrm{~cm}^{-1}\right)$ originating from PMMA structure in MG49 and PMMA. The vibration frequency of polymer-salt is then shifted to lower wavenumbers by about $15 \mathrm{~cm}^{-1}$ to $25 \mathrm{~cm}^{-1}$ as compared to their polymer host [15]. Fig. (1) represents the structure of PMMA grafted polyisoprene and its specific vibration modes.

Fig. (2a) shows the FT-IR spectrum of symmetrical stretching of carbonyl group, $v(\mathrm{C}=\mathrm{O})$ in MG49 and MG49PMMA blend as intense, very strong and sharp peaks at $1732 \mathrm{~cm}^{-1}$ in MG49 and at $1733 \mathrm{~cm}^{-1}$ in MG49-PMMA blend. With the addition of lithium salt, the intensity of $v(\mathrm{C}=\mathrm{O})$ peak is reduced and shifted from $1732 \mathrm{~cm}^{-1}$ to 1735 $\mathrm{cm}^{-1}$. However, this shifting is not significant enough for the carbonyl group since the resolution is only within $4 \mathrm{~cm}^{-1}$. Previous study reported that the shifting of the intensity peaks still occur even though in insignificant range. Kumutha et al. [16] reported that the $\mathrm{C}=\mathrm{O}$ stretching of PMMA at $1729 \mathrm{~cm}^{-1}$ is shifted to $1728 \mathrm{~cm}^{-1}$ in the MG30-EC with $\mathrm{LiCF}_{3} \mathrm{SO}_{3}$ salt complex. The symmetric stretching of polyisoprene in the rubber chain, $v_{s}(\mathrm{C}=\mathrm{C})$ at $1604 \mathrm{~cm}^{-1}$ can be used as an indicator to prove the interaction occurs in the polymer host. The non-polar structure in polyisoprene chain, 


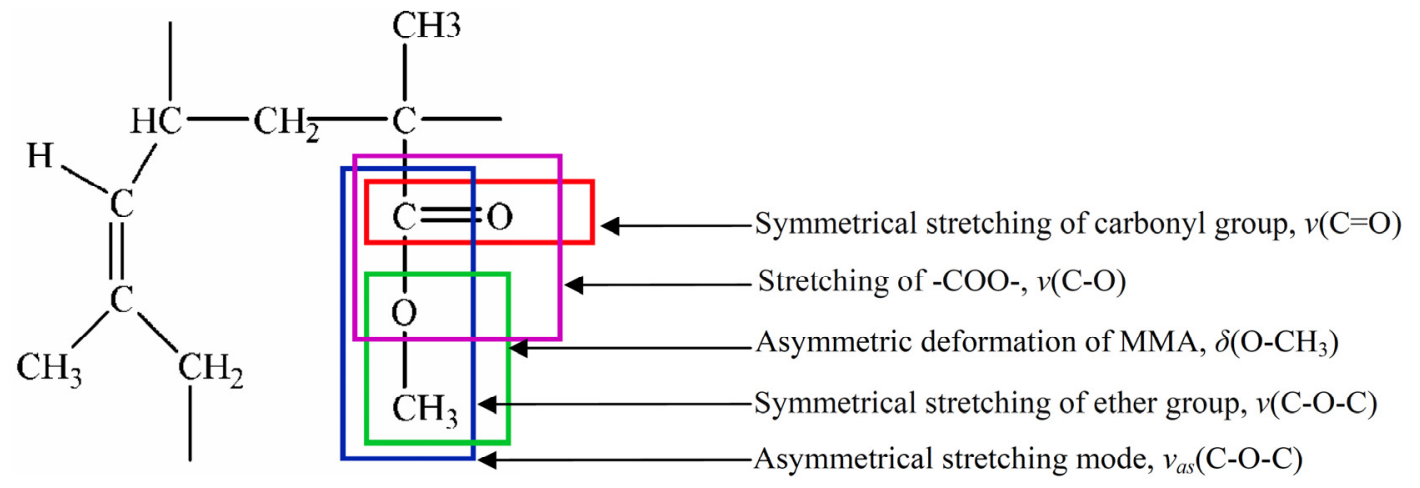

Fig. (1). Structure formula of PMMA grafted polyisoprene and its specific vibration mode.

$(\mathrm{C}=\mathrm{C})$ showed no changes in term of peak shifting or intensity in their vibration portion after the addition of lithium salts up to optimum level. Therefore, the shifting of the intensity peaks still occurs even though in insignificant range.

The specific vibration mode of ether group (C-O-C) in MG49 and MG49-PMMA blend can be observed in Fig. (2bd). It was observed that the vibration mode of $v(\mathrm{C}-\mathrm{O}-\mathrm{C})$, and $\delta\left(\mathrm{O}-\mathrm{CH}_{3}\right)$ at $984 \mathrm{~cm}^{-1}$ and $1457 \mathrm{~cm}^{-1}$ for pure MG49 were shifted to $992 \mathrm{~cm}^{-1}$ and $1450 \mathrm{~cm}^{-1}$ after blending with PMMA. This shifting was due to existence of intermolecular interaction between oxygen atoms with methylene group in the MMA moiety [14]. With the addition of $\mathrm{LiBF}_{4}$ salt, the intensity of $v(\mathrm{C}-\mathrm{O}-\mathrm{C}), v_{a s}(\mathrm{C}-\mathrm{O}-\mathrm{C})$ and $\delta\left(\mathrm{O}-\mathrm{CH}_{3}\right)$ of MMA peak was reduced and shifted to lower wavenumbers. The reduction of intensity and the shifting of wavenumbers can be clearly observed in the region where there has been an overlapping with the $\mathrm{LiBF}_{4}$ peak as shown in Fig. (2b-d).
The $\mathrm{LiBF}_{4}$ peaks are not seen in any of the polymer-salt complexes and this signifies that $\mathrm{LiBF}_{4}$ salt solvates very well in MG49-PMMA matrix, resulting in absence of pure salt phase in the complexes [14]. Fig. (2b) shows symmetrical stretching mode, $v(\mathrm{C}-\mathrm{O}-\mathrm{C})$ at $984 \mathrm{~cm}^{-1}$ and 992 $\mathrm{cm}^{-1}$ for pure MG49 and MG49-PMMA blend respectively. With the addition of $\mathrm{LiBF}_{4}$ salts, the intensity of $v(\mathrm{C}-\mathrm{O}-\mathrm{C})$ shoulders has reduced and shifted to $987 \mathrm{~cm}^{-1}$ in MG49 systems and $985 \mathrm{~cm}^{-1}$ in MG49-PMMA systems. Fig. (2c) shows asymmetrical stretching mode, $v_{a s}(\mathrm{C}-\mathrm{O}-\mathrm{C})$ at 1150 $\mathrm{cm}^{-1}$ and $1149 \mathrm{~cm}^{-1}$ for pure MG49 and MG49-PMMA blend respectively. With the presence of $20 \mathrm{wt} . \% \mathrm{LiBF}_{4}$ salts, the intensity of $v_{a s}(\mathrm{C}-\mathrm{O}-\mathrm{C})$ in MG49 systems has been reduced until it becomes lower than its neighbouring peak at 1178 $\mathrm{cm}^{-1}$.

The changes in $-\mathrm{CH}_{3}$ asymmetric deformation in the PMMA moiety, $\delta\left(\mathrm{O}-\mathrm{CH}_{3}\right)$ at $1450 \mathrm{~cm}^{-1}$ and $1457 \mathrm{~cm}^{-1}$ for pure MG49 and MG49-PMMA blend to $1461 \mathrm{~cm}^{-1}$ indicated

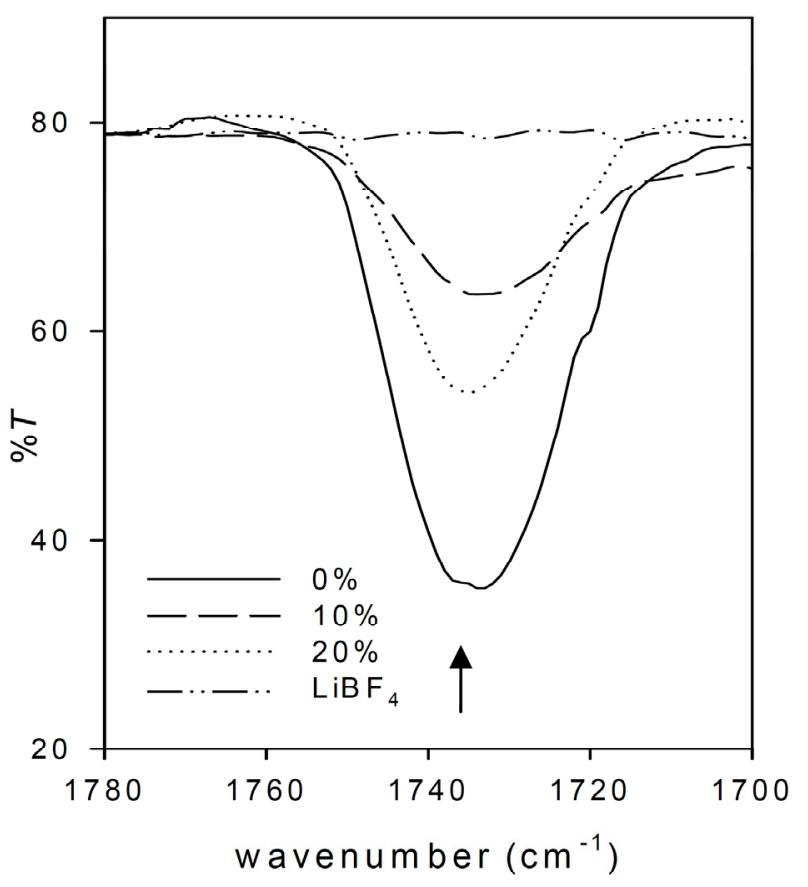

(i)

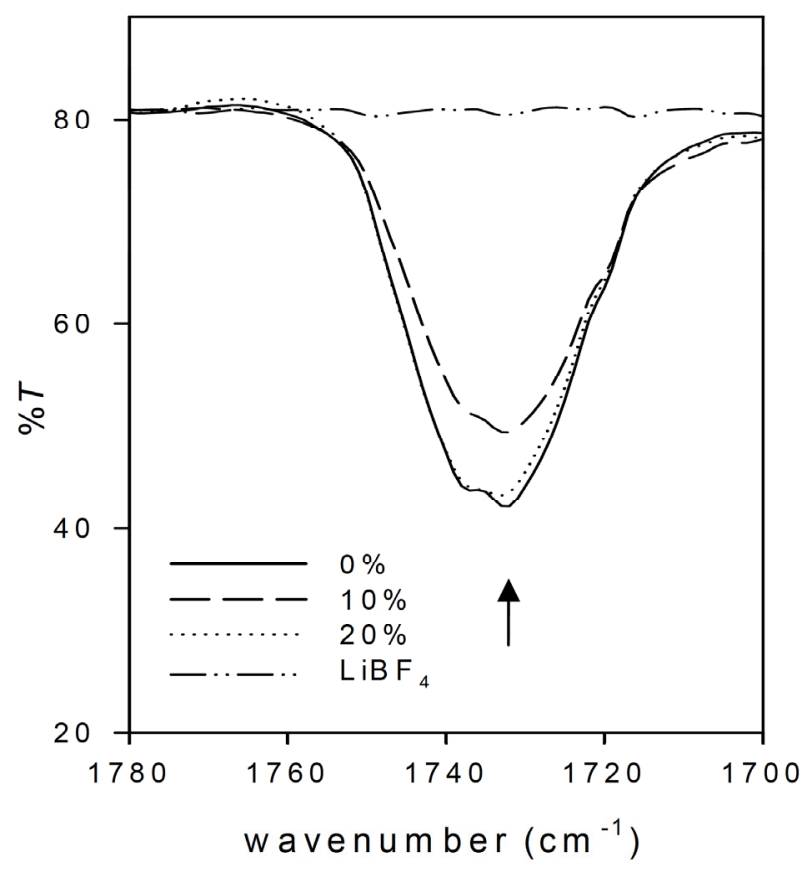

(ii)

Fig. (2a). FT-IR spectrum of symmetrical stretching of carbonyl group, $v(\mathrm{C}=\mathrm{O})$ (i) $\mathrm{MG} 49-\mathrm{LiBF}_{4}$ and (ii) $\mathrm{MG} 49-\mathrm{PMMA}^{-} \mathrm{LiBF}_{4}$. 


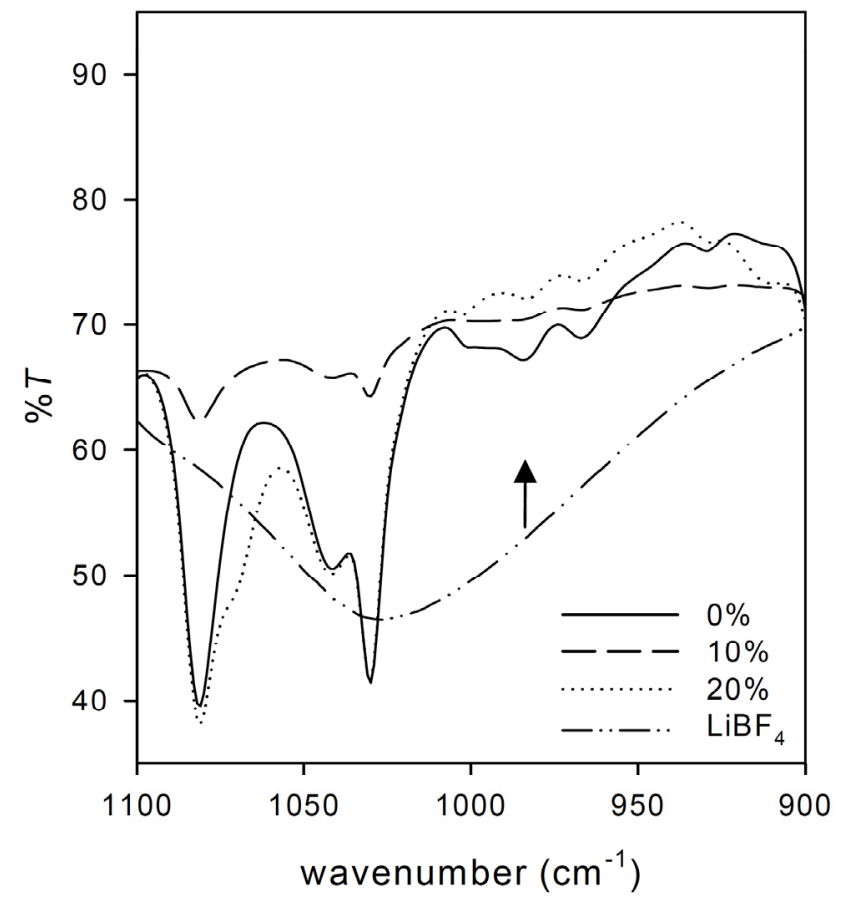

(i)

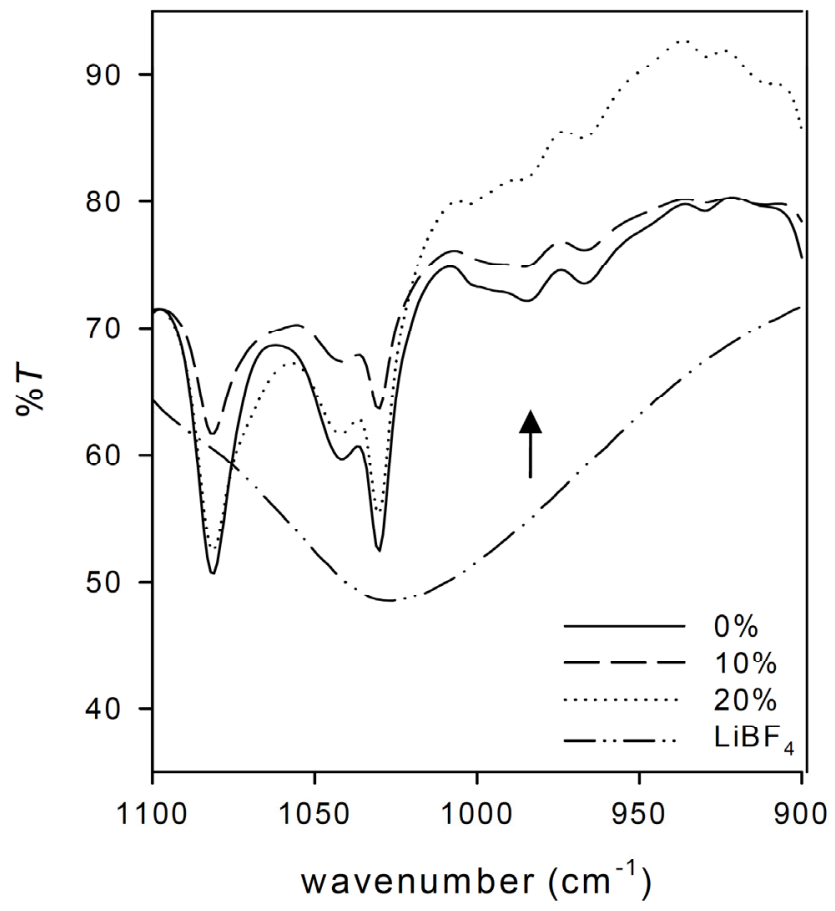

(ii)

Fig. (2b). FT-IR spectrum of symmetrical stretching of ether group, $v(\mathrm{C}-\mathrm{O}-\mathrm{C})$ (i) $\mathrm{MG}_{4}-\mathrm{LiBF}_{4}$ and (ii) MG49-PMMA-LiBF 4 .

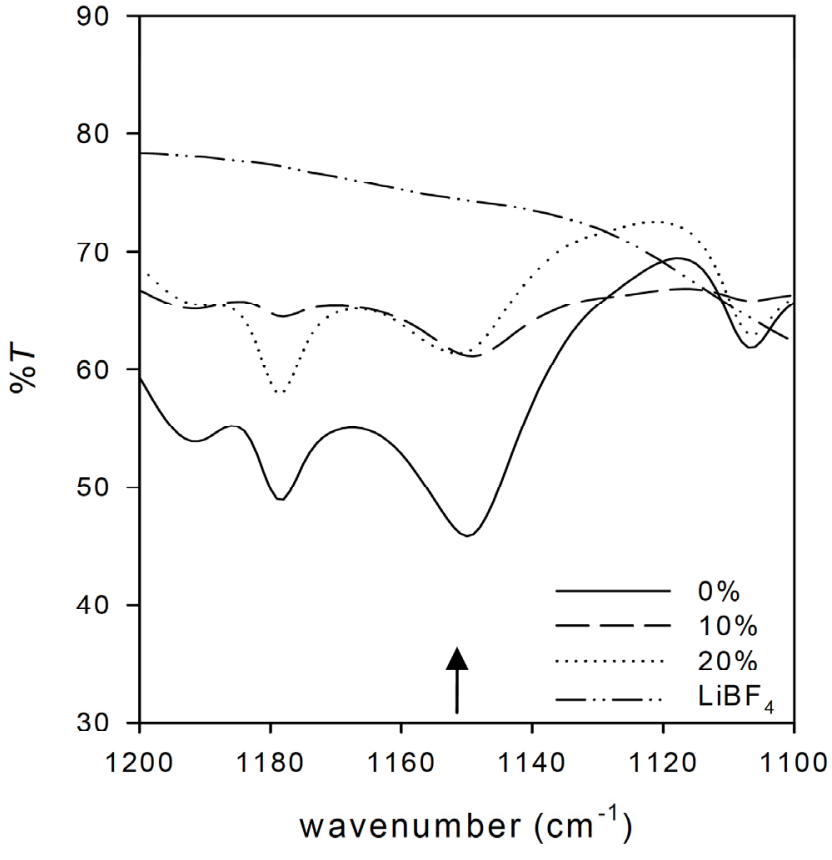

(i)

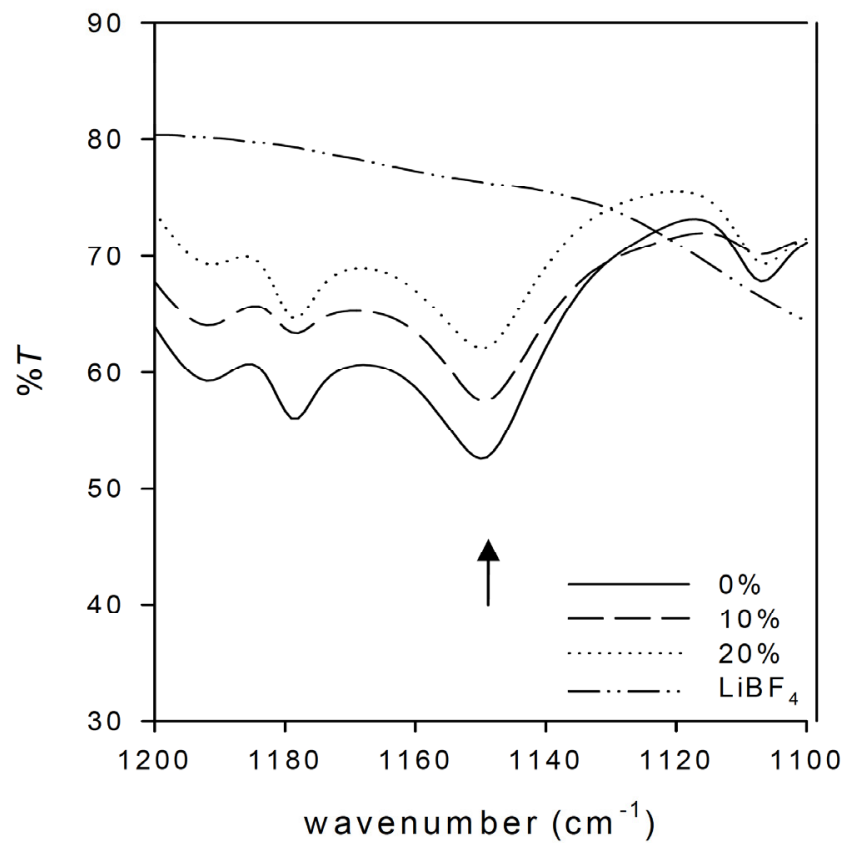

(ii)

Fig. (2c). FT-IR spectrum of asymmetrical stretching of ether group, $v_{a s}(\mathrm{C}-\mathrm{O}-\mathrm{C})$ (i) $\mathrm{MG} 49-\mathrm{LiBF}_{4}$ and (ii) $\mathrm{MG} 49-\mathrm{PMMA}-\mathrm{LiBF}$.

that the interaction between oxygen atoms and lithium ion were disturbed by the remaining vibration frequency of $\mathrm{O}-$ $\mathrm{CH}_{3}$ bonding as shown in Fig. (2d). This is because a coordinative/dative bond was formed between oxygen atoms and lithium ion. This leads to the formation of polymer-salt complexes. Based on this finding, we believe that the oxygen atom from ether group (C-O-C) contributed to the strong interaction with lithium cation. As a result, it affects the ionic mobility in the polymer electrolyte system. 


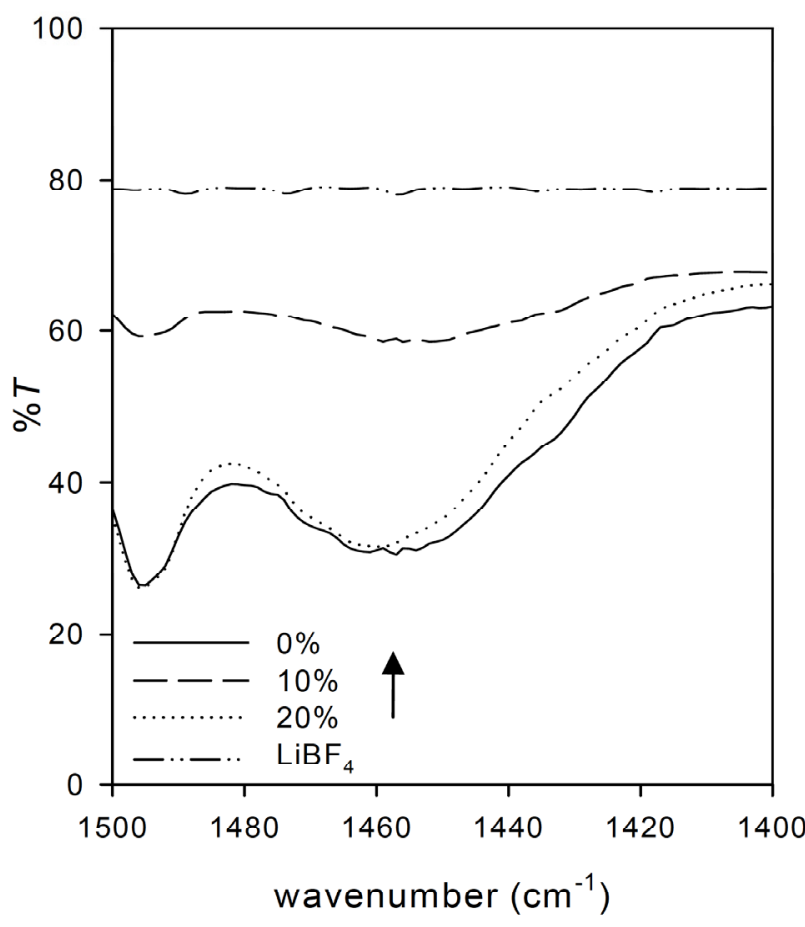

(i)

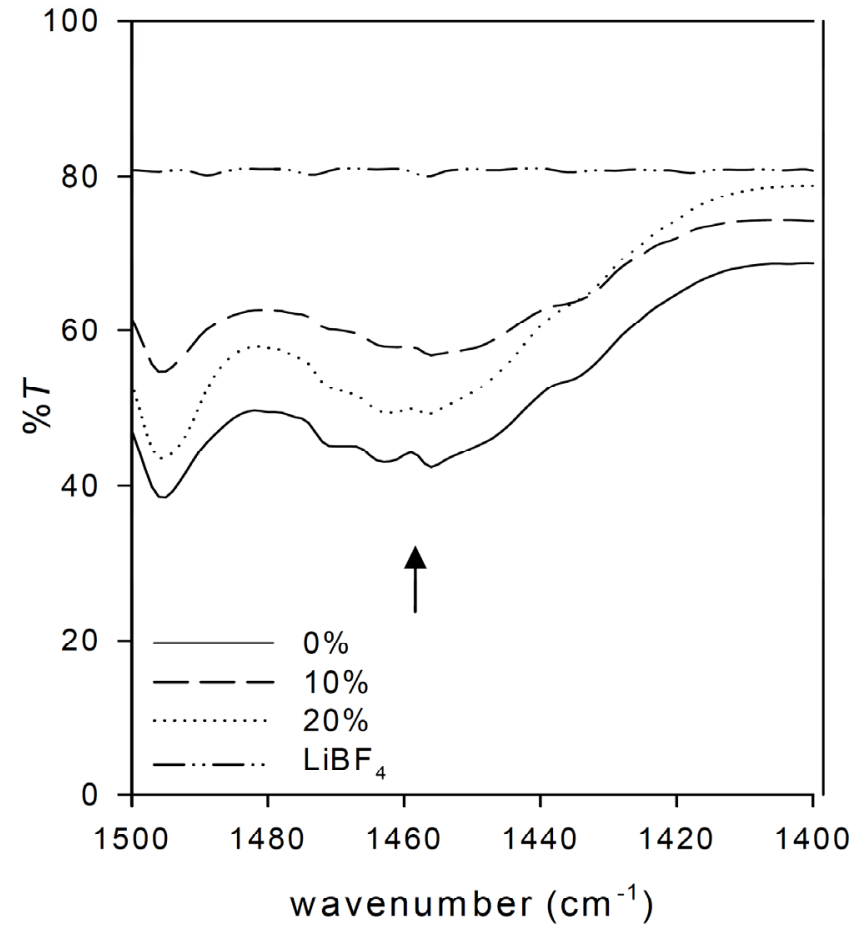

(ii)

Fig. (2d). FT-IR spectrum of asymmetric deformation of PMMA, $\delta\left(\mathrm{O}_{-} \mathrm{CH}_{3}\right)(\mathrm{i}) \mathrm{MG} 49-\mathrm{LiBF}_{4}$ and (ii) MG49-PMMA-LiBF 4 .

\section{Ionic Conductivity}

Ionic conductivity as well as $\left[\mathrm{O} / \mathrm{Li}^{+}\right]$ratio of MG49$\mathrm{LiBF}_{4}$ and MG49-PMMA-LiBF 4 are shown in Table $\mathbf{1}$ and has be interpreted in Fig. (3). Ionic conductivity MG49 without salt is $1.0 \times 10^{-12} \mathrm{~S} \mathrm{~cm}^{-1}$ and the highest conductivity is $2.3 \times 10^{-7} \mathrm{~S} \mathrm{~cm}^{-1}$ at 20 wt. $\%$ of $\mathrm{LiBF}_{4}$ salt addition as reported by our preliminary study on MG49 film [17]. After blending with $50 \%$ PMMA, MG49 without salt possess the conductivity of $1.7 \times 10^{-12} \mathrm{~S} \mathrm{~cm}^{-1}$ and highest conductivity value of $8.3 \times 10^{-6} \mathrm{~S} \mathrm{~cm}^{-1}$ is obtained at $25 \mathrm{wt}$. $\%$ of $\mathrm{LiBF}_{4}$ salt loading. The maximum value shows an effective interaction between oxygen atoms and lithium ion in this electrolyte system. The effective interaction can be expressed by the number of interaction between oxygen atoms to lithium ion or simply written as $\left[\mathrm{O} / \mathrm{Li}^{+}\right]$ratio. The $\left[\mathrm{O} / \mathrm{Li}^{+}\right]$ratio for the optimum MG49- $\mathrm{LiBF}_{4}$ salt loading is [8/1], while for MG49PMMA-LiBF 4 is $[5 / 1]$. The different value in the values of $\left[\mathrm{O} / \mathrm{Li}^{+}\right]$ratio is caused by the difference in the number of oxygen sites that of the free lithium ions. Ionic conductivity increases with the increasing of salt content until the maximum level in polymer host due to the increase of the $\mathrm{LiBF}_{4}$ salt content. Gray [2] in 1997 suggested that as the salt concentration in solution increased, the inter-ionic distance decreases and ion-ion interactions become more apparent. Ion dissociation mechanism of lithium salt and complexation in the rubber-polymer host has been suggested by Ahmad and co-workers in 2007 [18].

$$
\begin{aligned}
& \mathrm{LiBF}_{4} \rightarrow \mathrm{Li}^{+}+\mathrm{BF}_{4}^{-} \\
& \left.\mathrm{Li}^{+}+\mathrm{BF}_{4}^{-}+-(\mathrm{MMA})-\rightarrow \mathrm{BF}_{4}^{-} \text {[-(MMA)- }\right] \mathrm{Li}^{+}
\end{aligned}
$$

The increasing numbers of the conducting species in the electrolyte help to increase the conductivity value [19].
Furthermore, the increase in ionic conductivity with addition of PMMA is due to the increasing of the number of the coordinating sites. Carbonyl and ether group in PMMA provided an alternative pathway for ions to move from one site to another site. Nevertheless, the ionic conductivity decreases rapidly after the optimum salt addition in MG49$\mathrm{LiBF}_{4}$ because of the ion association or ion aggregation, which led to the re-crystallization of $\mathrm{LiBF}_{4}$ salts in the polymer host, as shown by XRD patterns in Fig. $(\mathbf{4 a}, \mathbf{b})$ and SEM micrograph in Fig. (5b), respectively.

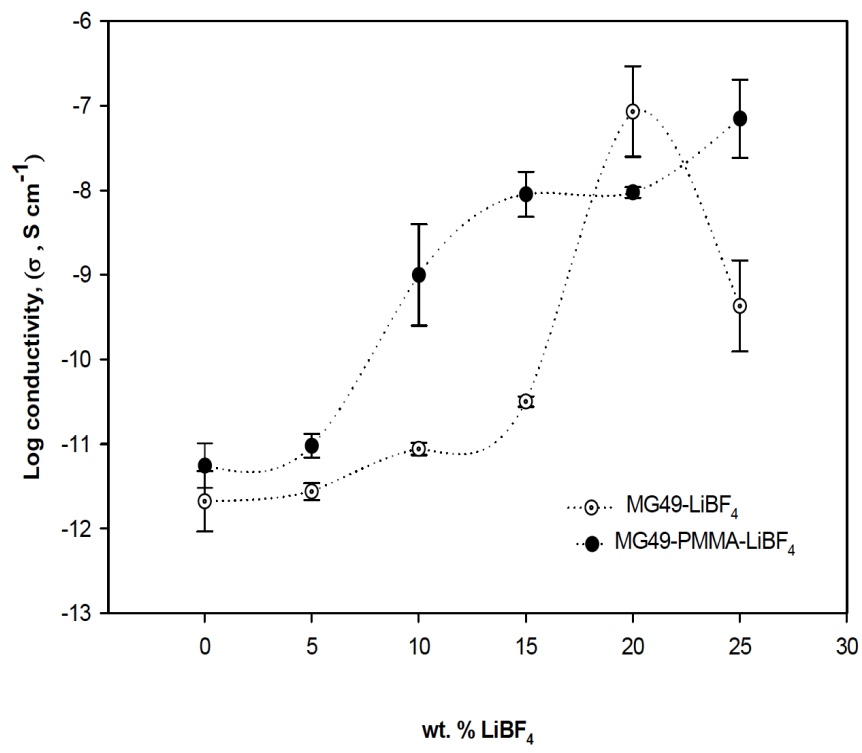

Fig. (3). Variation of ionic conductivity of $\mathrm{MG}_{4} 9-\mathrm{LiBF}_{4}$ and MG49-PMMA-LiBF 4 with $\mathrm{LiBF}_{4}$ content. 
Table 1. Ionic Conductivity and $\left[\mathrm{O} / \mathrm{Li}^{+}\right]$Ratio of MG49$\mathrm{LiBF}_{4}$ and MG49-PMMA-LiBF 4

\begin{tabular}{|c|c|c|c|c|}
\hline \multirow[b]{2}{*}{ wt. $\% \mathrm{LiBF}_{4}$} & \multicolumn{2}{|c|}{ MG49-LiBF 4} & \multicolumn{2}{|c|}{ MG49-PMMA-LiBF 4} \\
\hline & $\begin{array}{c}\text { Ionic } \\
\text { Conductivity } \\
\sigma\left(\mathrm{S} \mathrm{cm}^{-1}\right)\end{array}$ & $\begin{array}{c}{\left[\mathbf{O} / \mathbf{L i}^{+}\right]} \\
\text {Ratio }\end{array}$ & $\begin{array}{c}\text { Ionic } \\
\text { Conductivity } \\
\sigma\left(\mathrm{S} \mathrm{cm}^{-1}\right)\end{array}$ & $\begin{array}{c}{\left[\mathrm{O} / \mathrm{Li}^{+}\right]} \\
\text {Ratio }\end{array}$ \\
\hline 0 wt. $\%$ & $1.0 \times 10^{-12}$ & - & $1.7 \times 10^{-12}$ & - \\
\hline 5 wt. $\%$ & $9.7 \times 10^{-12}$ & $45 / 1$ & $8.4 \times 10^{-12}$ & $23 / 1$ \\
\hline 10 wt. $\%$ & $7.8 \times 10^{-12}$ & $23 / 1$ & $1.4 \times 10^{-8}$ & $12 / 1$ \\
\hline 15 wt. $\%$ & $3.0 \times 10^{-11}$ & $15 / 1$ & $2.6 \times 10^{-7}$ & $8 / 1$ \\
\hline 20 wt. $\%$ & $2.3 \times 10^{-7}$ & $11 / 1$ & $1.5 \times 10^{-7}$ & $6 / 1$ \\
\hline 25 wt. $\%$ & $9.6 \times 10^{-10}$ & $8 / 1$ & $8.3 \times 10^{-6}$ & $5 / 1$ \\
\hline
\end{tabular}

(a)

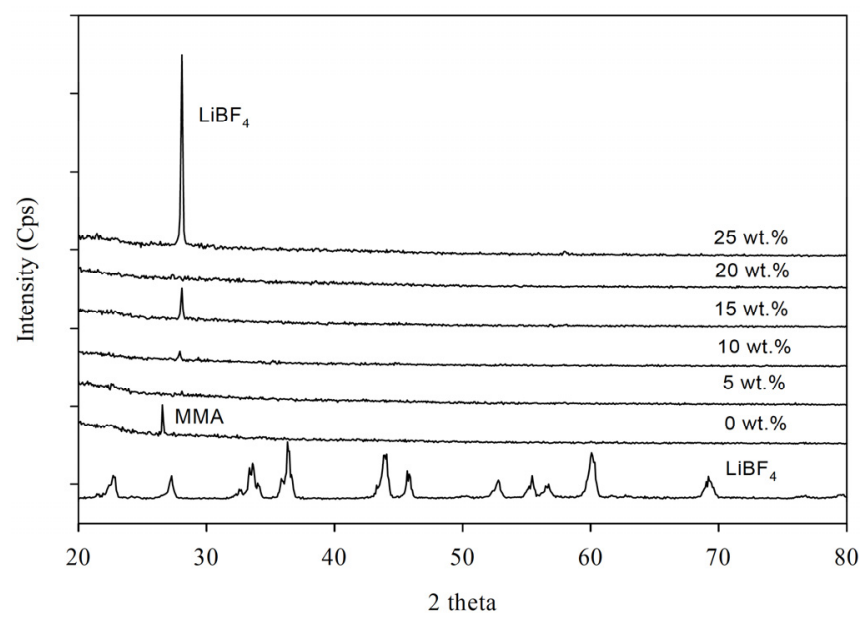

(b)

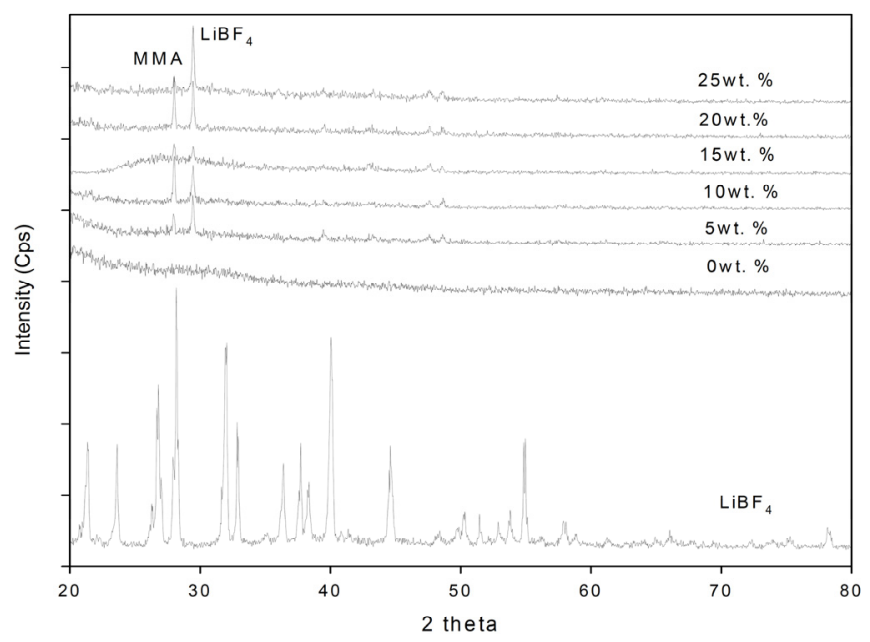

Fig. (4). XRD patterns of (a) MG49-LiBF 4 and (b) PMMA-MG49$\mathrm{LiBF}_{4}$.

\section{Structural Studies}

The XRD analysis is used to determine the structure and crystallization of polymer-salts complex by observing the appearance and disappearance of the crystalline or the amorphous region. The appearance of amorphous region or the reduction of crystalline region would give a high ionic conductivity as compared to the crystalline or semicrystalline region as shown by others [2,3,20-22]. Fig. (4) shows the XRD patterns of (a) MG49- $\mathrm{LiBF}_{4}$ and (b) MG49PMMA-LiBF 4 . Pure MG49 in Fig. (4a) shows a single peak at $26.6^{\circ}$ that belongs to semi-crystalline phases of PMMA monomer grafted in rubber chain. With the addition of lithium salt from 5 to 25 wt. \%, the PMMA single peak at $26.6^{\circ}$ disappears. While in Fig. (4b), the similar peak appears after the addition of $\mathrm{LiBF}_{4}$ salts in MG49-PMMA system. Others PMMA peaks are also observed after the addition of $\mathrm{LiBF}_{4}$ salts in MG49-PMMA system at $29.4^{\circ}$, $47.6^{\circ}$ and $48.5^{\circ}$. Similar to our previous study on MG49PMMA at blend ratio (30/70) [8], a maximum ionic conductivity value still occurs due to the reduction of the PMMA peak intensity from hump shape to a broadening shape. The reduction of hump shape in Fig. (4b) shows the semi-crystalline region occurs in the PMMA is decreased with the addition of salt up to the optimum conductivity.

The presence of $\mathrm{LiBF}_{4}$ peaks can be observed at the angle $28^{\circ}$ for both systems. With the addition of $50 \mathrm{wt}$. \% PMMA, the intensity of this peak reduced by two magnitudes. The presence of $\mathrm{LiBF}_{4}$ peaks shows that the crystalline phase occurred in the electrolyte system. Ions association or ions aggregation has led to the re-crystallization of $\mathrm{LiBF}_{4}$ salts in the polymer host, as shown in the SEM micrograph in Fig. (5d). Therefore, it provides low conductivity despite the addition of $\mathrm{LiBF}_{4}$ salt archives its maximum level. The addition of salt affects the overall ionic conductivity through the formation of crystalline complexes and degree of salts dissociation-number of charge carriers [2].

\section{Morphology Studies}

Morphology analysis was carried out by SEM to investigate the effect of PMMA and $\mathrm{LiBF}_{4}$ salts content on the fractured surface of the MG49. Fig. (5a) shows the SEM micrograph of MG49 with (i) 0 wt. \%, (ii) 15 wt. \%, (iii) 20 wt. $\%$ and (iv) 25 wt. $\% \mathrm{LiBF}_{4}$ salts meanwhile, Fig. (5b) shows the SEM micrograph of MG49-PMMA with (i) 0 wt. $\%$, (ii) 15 wt. $\%$ and (iii) 25 wt. $\% \mathrm{LiBF}_{4}$ salts. SEM micrograph in Fig. (5a) (i) shows a homogenous surface of rubber film using solution blending technique. Flexibility and elasticity properties of the rubber film were attributed by the polyisoprene segment in MG49, while the hard segment was contributed by the PMMA that has been grafted onto rubber chain [16]. The structure of MMA grafted polyisoprene (MG49) has been shown in Fig. (1). SEM micrograph in Fig. (5b) (i) shows a homogenous and miscible surface of rubber-polymer blends film using the same technique. In addition, no phase separation is observed in this system. This observation is an indication of the existence of intermolecular interactions between oxygen atoms with methylene group originating in the PMMA moiety, as discussed by Ali et al. [23]. However, the physical properties of the rubber-polymer blends film were not as flexible and elastic as rubber film due to the brittles properties of PMMA.

Fig. (5a) (ii) and (iii) indicated that most of $\mathrm{LiBF}_{4}$ salt were dissociated into $\mathrm{Li}^{+}$and $\mathrm{BF}_{4}{ }^{-}$species since there is no 

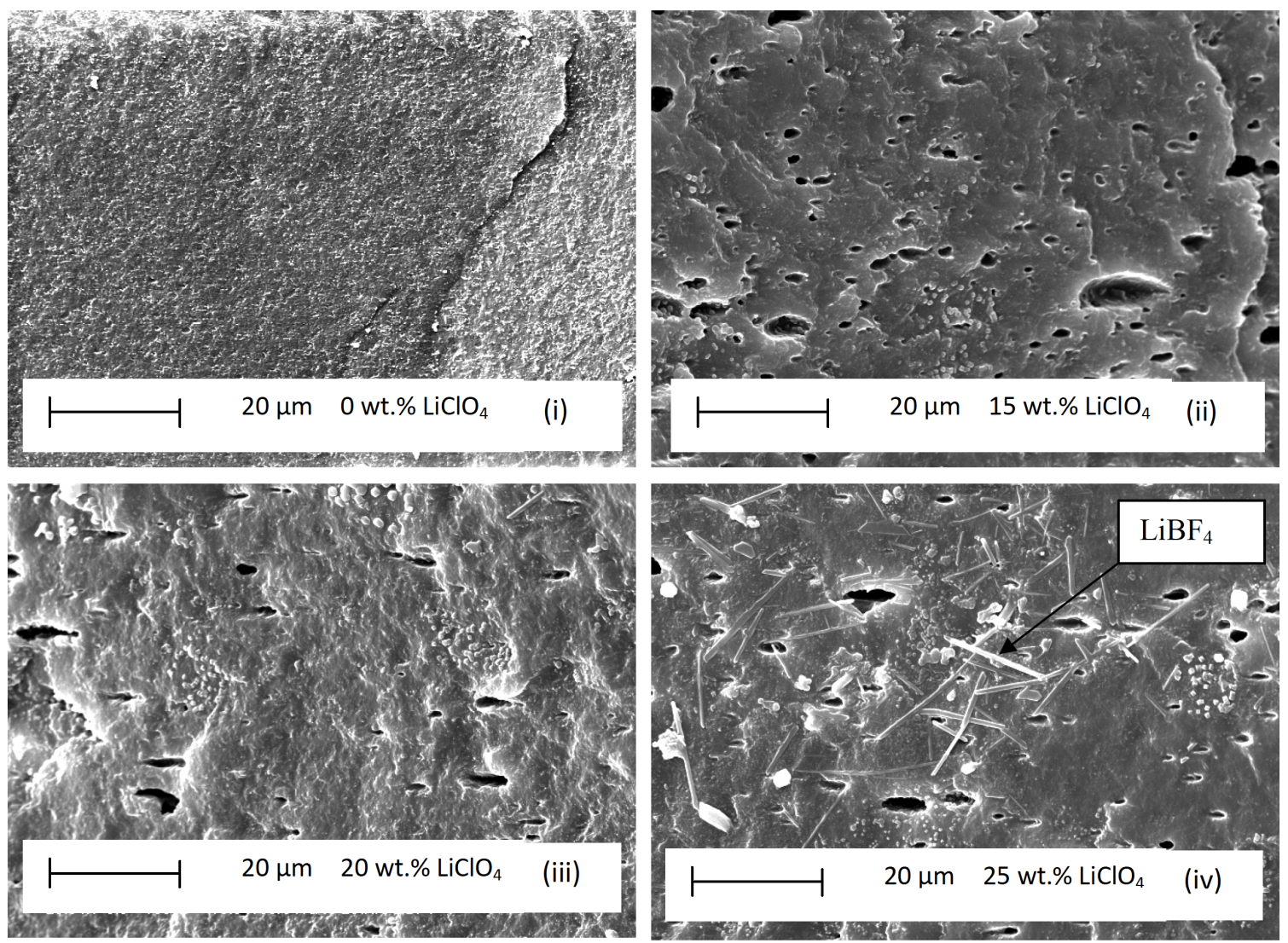

Fig. (5a). SEM micrograph of MG49 with (i) 0 wt. \% (ii) 15 wt. \% (iii) 20 wt. \% (iv) 25 wt. \% LiBF 4 salt.
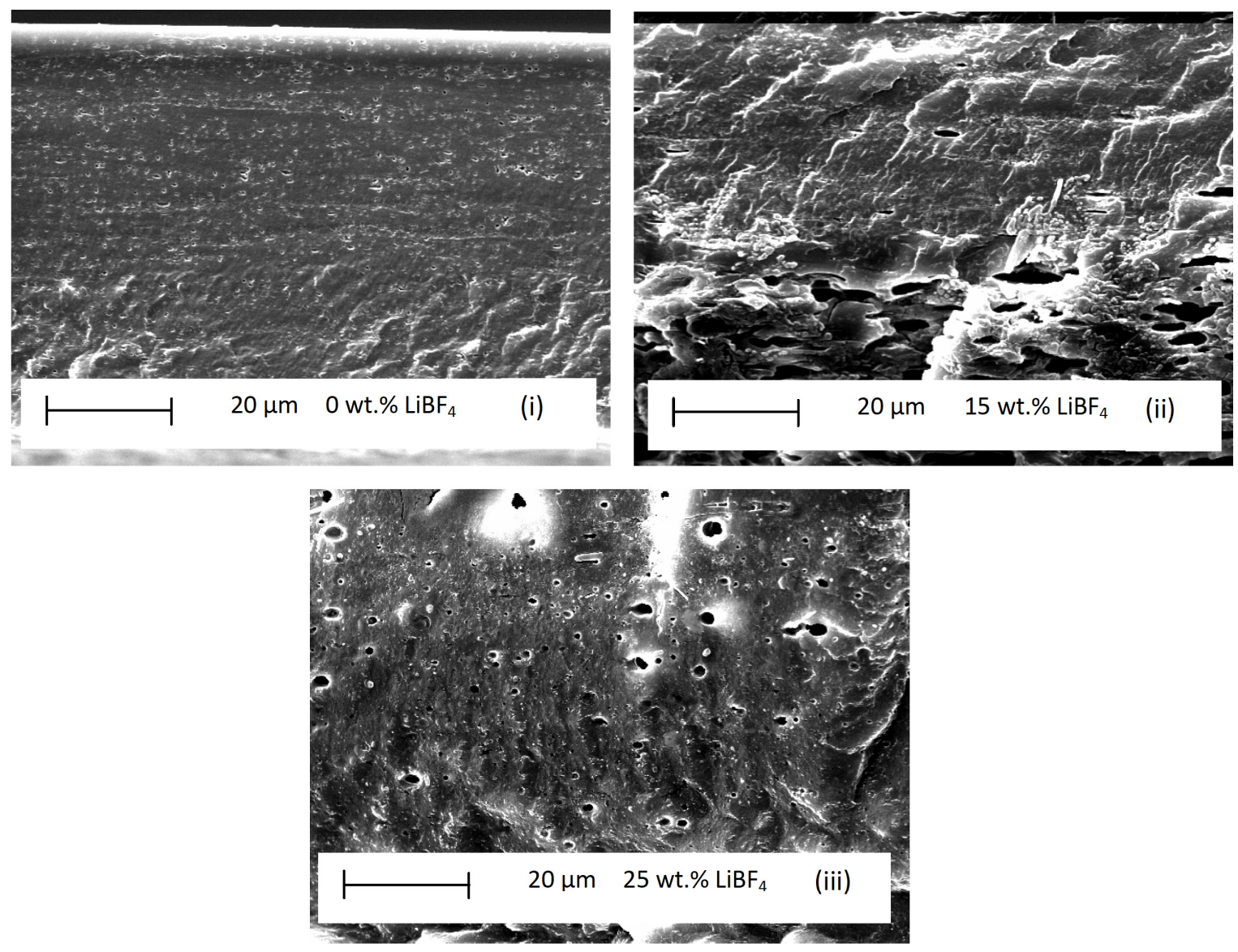

Fig. (5b). SEM micrograph of MG49-PMMA with (i) 0 wt. \% (ii) 15 wt. \% (iii) 25 wt. \% LiBF 4 salt. 
crystal structure that can be traced. Thus, this provides a higher concentration of ions to freely move and increased the ionic conductivity value from $\sim 10^{-12} \mathrm{~S} \mathrm{~cm}^{-1}$ to $\sim 10^{-6} \mathrm{~S} \mathrm{~cm}^{-1}$ $[2,20]$. The cross-sectional view of the sample in Fig. (5a) (ii) \& (iii) and 5 (b) (ii) \& (iii) shows the formation of micropores. The formation of these micropores is due to the interaction between the solvent and polymer host as reported by Ahmad et al. [24]. According to their finding, the absence of pores will give a compensating effect on the transport properties of $\mathrm{Li}^{+}$ions by increasing the surface area and such improving the conductivity of the electrolyte. The recrystallization of $\mathrm{LiBF}_{4}$ salt observed in Fig. (5a) (iv) has been confirmed by structural analysis at the addition of 25 wt. $\% \mathrm{LiBF}_{4}$ salt. Re-crystallization of $\mathrm{LiBF}_{4}$ salt was due to the high concentration salt in the electrolyte system. A high concentration salt gives a high tendency to the ionic species to associate or aggregate with each other. The tendency of the ionics species to associates or aggregates will decreases the number of the conducting species and decreases the ionic mobility in the electrolyte. Ion association or ion aggregation has led to the re-crystallization of $\mathrm{LiBF}_{4}$ salts in the polymer host. Thus, it disturbed the ionic mobility as it congested the ionic migration in the segmental polymer chain. As a consequence, the ionic conductivity decreases after the optimum salt loading in MG49-LiBF 4 [25]. The effects of this phenomenon has been proven and discussed in the previous section.

\section{CONCLUSIONS}

Solid polymer electrolyte MG49 and blended MG49PMMA doped with $\mathrm{LiBF}_{4}$ salt can be successfully prepared by solution casting technique. There is an interaction between oxygen atoms in the ether and carbonyl groups and lithium ions, which can be detected by infrared spectrometry. At the highest conductivity, $8.3 \times 10^{-6} \mathrm{~S} \mathrm{~cm}^{-1}$ the crystalline phase is reduced. Re-crystallization of $\mathrm{LiBF}_{4}$ salt can occur in the electrolyte system after $25 \mathrm{wt}$. $\%$ of $\mathrm{LiBF}_{4}$ salt.

\section{ACKNOWLEDGEMENTS}

The authors would like to extend their gratitude to Universiti Kebangsaan Malaysia for allowing this research to be carried out. This work is supported by the MOSTI grant 03-01-02-SF0423.

\section{REFERENCES}

[1] Fenton DE, Parker JM, Wright PV. Complexes of Alkali Metal Ions with PEO. Polymer 1973; 14: 589.

[2] Gray FM. Polymer Electrolytes. London: RCS Monographs 1997.

[3] Glasse MD, Idris R, Latham RJ, Linford RG, Schlindwein WS. Polymer Electrolytes Based on Modified Natural Rubber PEOENR25/ENR-50-LiCF $\mathrm{SO}_{3}$. Solid State Ionics 2002; 147: 289-94.

[4] Latif F, Aziz AM, Katun N, Ali AMM, Yahya MZA. The Role and Impact of Rubber in PMMA- $\mathrm{LiCF}_{3} \mathrm{SO}_{3}$ Electrolytes. J Power Sources 2006; 159: 1401-4.
[5] Kumutha K, Alias Y. FTIR Spectra of Plasticized Grafted NR$\mathrm{LiCF}_{3} \mathrm{SO}_{3}$ Electrolytes. Spectrochim Acta Part A 2006; 64: 442-7.

[6] Ali AMM, Subban RHY, Bahron H, Winie T, Latif F, Yahya MZA. Grafted Natural Rubber-Based Polymer Electrolytes, ATRFTIR and Conductivity Studies. Ionics 2007; 14: 491-500.

[7] Alias Y, Ling I, Kumutha K. Structural and Electrochemical Characteristics of 49\% PMMA Grafted Polyisoprene (MG49)$\mathrm{LiCF}_{3} \mathrm{SO}_{3}-\mathrm{PC}$ Based Polymer Electrolytes. Ionics 2005; 11: 414-7.

[8] Su'ait MS, Ahmad A, Hamzah H, Rahman MYA. Preparation and characterization of PMMA-MG49- $\mathrm{LiClO}_{4}$ solid polymeric electrolyte. J Physics D 2009; 42: 55410.

[9] Idris R, Glasse MD, Latham RJ, Linford RG, Schlindwein WS. Polymer Electrolytes Based on Modified NR for use in Rechargeable Lithium Batteries. J Power Sources 2001; 94: 20611.

[10] Lu G, Li Z-F, Li S-D, Xie J. Blends of Natural Rubber Latex and Methyl Methacrylate-Grafted Rubber Latex. J Appl Polym Sci 2001; 85: 1736-41.

[11] Iijima T, Tyoguchi Y, Eda N. Quasi-Solid Organic Electrolytes Gelatinized with PMMA and their Applications for Lithium Batteries. Dengki Kagaku 1985; 53: 619.

[12] Rajendran S, Mahendran O, Kannan R. Characterisation of [(1$x)$ PMMA- $x$ PVdF] Polymer Blend Electrolyte with $\mathrm{Li}^{+}$ion. Fuel 2002; 81: 1077-81.

[13] Rajendran S, Uma T, Mahalingam T. Characterization of Plasticized PMMA Based Solid Polymer Electrolytes. Ionics 1999; 5: $232-5$.

[14] Noor SAM, Ahmad A, Talib IA, Rahman MYA. Morphology, Chemical Interaction, and Conductivity of a PEO-ENR50 Based Solid Polymer Electrolyte. Ionics 2010; 16: 161-70.

[15] Pavia DL, Lampman GM, Kriz GS (2001) Introduction to Spectroscopy, $3^{\text {rd }}$ ed. Califonia, USA: Brooks/Cole Publishing, 2001

[16] Kumutha K, Alias Y, Said R. FTIR and Thermal Studies of Modified NR Based Solid Polymer Electrolytes. Ionics 2005; 11: $472-6$.

[17] Su'ait MS, Ahmad A, Rahman MYA. Ionic Conductivity Studies of $49 \%$ Poly(Methyl Methacrylate)-Grafted Natural Rubber Based Solid Polymer Electrolytes. Ionics 2009; 15: 497-500.

[18] Ahmad A, Rahman MYA, Ali MLM. Solid Polimer Electrolyte of PVC-ENR-LiClO 4 . Ionics 2007; 13: 67-70.

[19] Wang HX, Wang ZX, Li H, Meng QB, Chen LQ. Ion Transport in Small-Molecule Electrolytes Based on LiI/3-Hydroxypropionitrile with High Salt Contents. Electrochim Acta 2006; 52: 2039-44.

[20] Mahendran O, Rajendran S. Ionic Conductivity Studies in PMMA/PVdF Polymer Blend Electrolyte with Lithium Salts. Ionics 2003; 9: 282-8.

[21] Subban RHY, Arof AK. Experimental Investigations on PVC$\mathrm{LiCF}_{3} \mathrm{SO}_{3}-\mathrm{SiO}_{2}$. Composite Polymer Electrolytes. J New Mater Electrochem Syst 2003; 6: 197-203.

[22] Baskaran R, Selvasekarapandian S, Kuwata N, Kawamura J, Hattori T. Conductivity and Thermal Studies of Blends SPE Based on PVAc-PMMA. Solid State Ionics 2006; 177: 2679-82.

[23] Ali AMM, Yahya MZA, Bahron H, Subban RHY. Electrochemical Studies on Polymer Electrolytes Based on Poly(Methyl Methacrylate)-Grafted Natural Rubber for Lithium Polymer Battery. Ionics 2006; 12: 303-7.

[24] Ahmad A, Rahman MYA, Su'ait MS. Preparation and Characterization of $\mathrm{PVC}_{-} \mathrm{LiClO}_{4}$ based Composite Polymer Electrolyte. Physica B 2008; 403: 4128-31.

[25] Tang Z, Wang J, Chen Q, He W, Shen C, Mao X, Zhang J. A Novel PEO Based Composite Polymer Electrolyte with Absorptive Glass Mat for Li-Ion Batteries. Electrochim Acta 2007; 52: 663743. 